\title{
DETERMINATION OF THE $\gamma^{6}$-SOLVUS TEMPERATURE OF TWO COMMERCIAL WROUGHT NI-BASE SUPERALLOYS BY THERMAL EXPANSION MEASUREMENTS
}

\author{
Wolgang Hermann ${ }^{1}$, Michael Fahrmann ${ }^{2}$, Hans-Georg Sockel ${ }^{3}$ \\ ${ }^{1}$ Siemens Power Generation, Mülheim, Germany \\ ${ }^{2}$ Special Metals Corporation, Huntington, West Virginia, USA \\ ${ }^{3}$ Institut für Werkstoffwissenschaften, Universität Erlangen-Nürnberg, Germany
}

Keywords: wrought Ni-base superalloys, $\gamma^{\prime}$ solvus temperature, thermal expansion measurement, differential thermal analysis

\begin{abstract}
The $\gamma^{\prime}$-solvus temperatures of two commercial wrought Ni-base superalloys, i.e, WASPALOY and NIMONIC ${ }^{\circledR}$ alloy 80A, were determined independently by differential thermal analysis (DTA), measurement of the coefficient of thermal expansion (CTE) and by standard metallographic techniques. Special attention was paid to the effects of repeated cycles, and heating and cooling rates when measuring inflection points indicative of the respective transus temperatures. The results of the various independent techniques are compared and their industrial relevance is discussed.
\end{abstract}

\section{Introduction}

Nickel-base superalloys are engineering materials combining outstanding high temperature strength, superior environmental resistance and microstructural stability and are the materials of choice for hot sections of gas turbines. Their excellent high temperature strength arises mainly from the homogeneous precipitation of cuboidal $\gamma^{\prime}$-precipitates, a $\mathrm{L1}_{2}$ ordered intermetallic $\mathrm{Ni}_{3} \mathrm{Al}$ phase, in a Ni-rich austenitic $\gamma$-matrix. The ascast condition, however, typically features $\gamma^{\prime}$-precipitates of irregular shape and some amount of $\gamma-\gamma^{\prime}$-eutectic, which reduces strength and ductility of the material.

In order to obtain an optimum microstructure and the desired high temperature properties, these alloys generally require multi-stage heat treatments. This involves heating to a temperature above the $\gamma^{\prime}$ solvus temperature to dissolve the coarse $\gamma^{\prime}$ structure, followed by rapid cooling and re-heating to a temperature below the $\gamma^{\prime}$ solvus for controlled re-precipitation of the $\gamma^{\prime}$-phase on a fine scale. For wrought $\gamma^{\prime}$ hardened Ni-base superalloys, knowledge of the $\gamma^{\prime}$ solvus temperature is equally crucial for devising proper heat treatment and thermo-mechanical processing schedules.

Traditionally, respective solvus temperatures have been determined either by metallographic examination of a series of samples aged at various temperatures in the vicinity of the $\gamma$ ' solvus, or by differential thermal analysis (DTA). The metallographic determination of the $\gamma^{\prime}$-solvus is fairly accurate but costly and time-consuming. DTA techniques usually require rather high heating rates to obtain a signal that can be analyzed. For that reason, the measurement often does not occur in the thermal equilibrium, and thus the apparent $\gamma^{\prime}$-solvus is shifted to higher temperatures.

Alternatively, the potential of exploiting characteristics of the thermal expansion behavior has been indicated in the literature $[1,2]$, but not rigorously explored. In comparison with the former techniques, the thermal expansion method appears to offer a number of advantages such as

- $\quad$ probing of significantly larger samples (on the order of 5-7 g versus $200 \mathrm{mg}$ typical of DTA specimens), thus improving the statistical relevance of the results,

- $\quad$ allowing to perform experiments at very low heating rates (1 $\mathrm{K} / \mathrm{min}$ versus $5 \mathrm{~K} / \mathrm{min}$ and higher typical of DTA runs), thus diminishing any kinetic effects associated with the dissolution of $\gamma^{\prime}$,

- being significantly less labor-intensive than the metallographic method.

The aim of this work was to ascertain the viability of the thermal expansion method by benchmarking it against the more traditional, generally accepted methods. To this end, sample material originating from commercial heats of two wellestablished, $\gamma$ '-hardenable wrought Ni-base superalloys, i.e., WASPALOY and NIMONIC alloy 80A, was studied extensively. Special consideration was given to the effect of initial microstructures, and instrument operational parameters (heating and cooling rates), on the reliable and reproducible measurement of $\gamma^{\prime}$ solvus temperature.

\section{Experimental}

$\underline{\text { Investigated Materials }}$

Sample material in various mill product forms was available from commercial heats of NIMONIC alloy $80 \mathrm{~A}$ as well as Waspaloy. The chemical compositions of the investigated heats are shown in Table 1. These alloys are known to form $\gamma$ ' after standard heat treatments.

Prior to $\gamma$-solvus measurements, all samples received the respective standard heat treatments as stated in Table 2. Also noted is the average grain size per ASTM E 112 of the material in the as-heat treated condition.

\footnotetext{
${ }^{\circledR}$ NIMONIC is a trademark of the Special Metals
}

Corporation family of companies 
Table 1: Chemical composition (in wt.\%) of the investigated wrought Ni-base superalloys.

\begin{tabular}{|c|c|c|c|c|c|c|c|c|c|}
\hline alloy & Ni & Co & Fe & Cr & Mo & Al & Ti & Nb & C \\
\hline Waspaloy & bal. & 13.5 & $<1.0$ & 19.7 & 4.3 & 1.4 & 3.0 & $<0.1$ & .030 \\
\hline NIMONIC alloy 80A & bal. & 0.1 & 0.4 & 19.5 & $<0.1$ & 1.4 & 2.6 & $<0.1$ & .075 \\
\hline
\end{tabular}

Table 2: $\quad$ Summary of the standard heat treatments and resulting ASTM grain size of the investigated wrought Ni-base superalloys.

\begin{tabular}{|c|c|c|c|}
\hline alloy & annealing heat treatment & precipitation heat treatment & $\begin{array}{c}\text { ASTM grain size } \\
\text { number }\end{array}$ \\
\hline Waspaloy & $1020{ }^{\circ} \mathrm{C} / 4 \mathrm{~h}$, oil quench & $\begin{array}{c}850{ }^{\circ} \mathrm{C} / 4 \mathrm{~h}, \mathrm{AC} \\
+760{ }^{\circ} \mathrm{C} / 16 \mathrm{~h}, \mathrm{AC}\end{array}$ & $91 / 2$ \\
\hline NIMONIC alloy $80 \mathrm{~A}$ & $1080{ }^{\circ} \mathrm{C} / 8 \mathrm{~h}$, water quench & $70{ }^{\circ} \mathrm{C} / 16 \mathrm{~h}, \mathrm{AC}$ & $91 / 2$ \\
\hline
\end{tabular}

Table 3: $\quad$ Main operating parameters of the two DTA cells employed in this study.

\begin{tabular}{|c|c|c|c|c|c|}
\hline DTA cell & $\begin{array}{c}\text { reference } \\
\text { sample }\end{array}$ & atmosphere & $\begin{array}{c}\text { flow rate } \\
{[\mathbf{c c} / \mathbf{m i n}]}\end{array}$ & $\begin{array}{c}\text { heating rates } \\
{[\mathbf{K} / \mathbf{m i n}]}\end{array}$ & $\begin{array}{c}\text { cooling rates } \\
{[\mathbf{K} / \mathbf{m i n}]}\end{array}$ \\
\hline TA $1600(\mathrm{~A})$ & alumina & helium & 40 & $5 \ldots 40$ & 20 \\
\hline TA $1600(\mathrm{~B})$ & alumina & argon & 40 & $5 \ldots 40$ & $1 \ldots 30$ \\
\hline
\end{tabular}

\section{Thermal Expansion Measurements}

Thermal expansion was measured by a computer controlled pushrod vertical dilatometer featuring a high resolution [3]. With this dilatometer, absolute changes in length of $40 \mathrm{~nm}$ can be measured for a sample length of $30 \mathrm{~mm}\left(10^{-6}\right.$ relative resolution).

This dilatometer consists chiefly of a double wall alumina tube, an alumina push-rod, a movable furnace, the inductive displacement measurement system, and a personal computer for process control and data acquisition (Figure 1). The inner alumina tube contains the sample support, the thermocouple and guides the push rod, while the outer tube acts as a vacuum chamber. The alumina push-rod is carefully balanced by a counter weight to avoid pressure on the sample and an impression of the push-rod into the sample at temperatures near the melting point. All alumina parts are well annealed to guarantee a reproducible thermal expansion. The change in length is measured inductively by a LVDT (linear variable differential transformer) at the tip of the push-rod inside a casing, and are sent via a carrier frequency amplifier to the personal computer for further evaluation. The casing and the alumina tubes are kept under a vacuum of $10^{-3}$ mbar to prevent oxidation of the sample because a growing oxide layer can falsify the measurements.

Special efforts were made to keep the casing with the measurement equipment at a constant temperature of $20^{\circ} \mathrm{C}$ in order to perform the measurements under reproducible conditions. This required several measures such as a bath-thermostat, several cooling coils inside the casing, the cooling of the LVDT and the connection of the alumina tubes to the casing by a water-cooled flange and an additional watercooled shielding (Figure 1).

The calibration of the dilatometer was performed very carefully according to German Industrial Standard DIN EN 51045 against an alumina standard for a sample length of $30 \mathrm{~mm}$ to guarantee the desired accuracy and reproducibility of the measurements. For the investigations a sample length of $30 \mathrm{~mm}$ was consistently used to prevent variations in the temperature distributions in the push-rod as would be encountered when employing different length specimens. The measurements were performed with constant heating and cooling rates between 1 and $20 \mathrm{~K} / \mathrm{min}$.

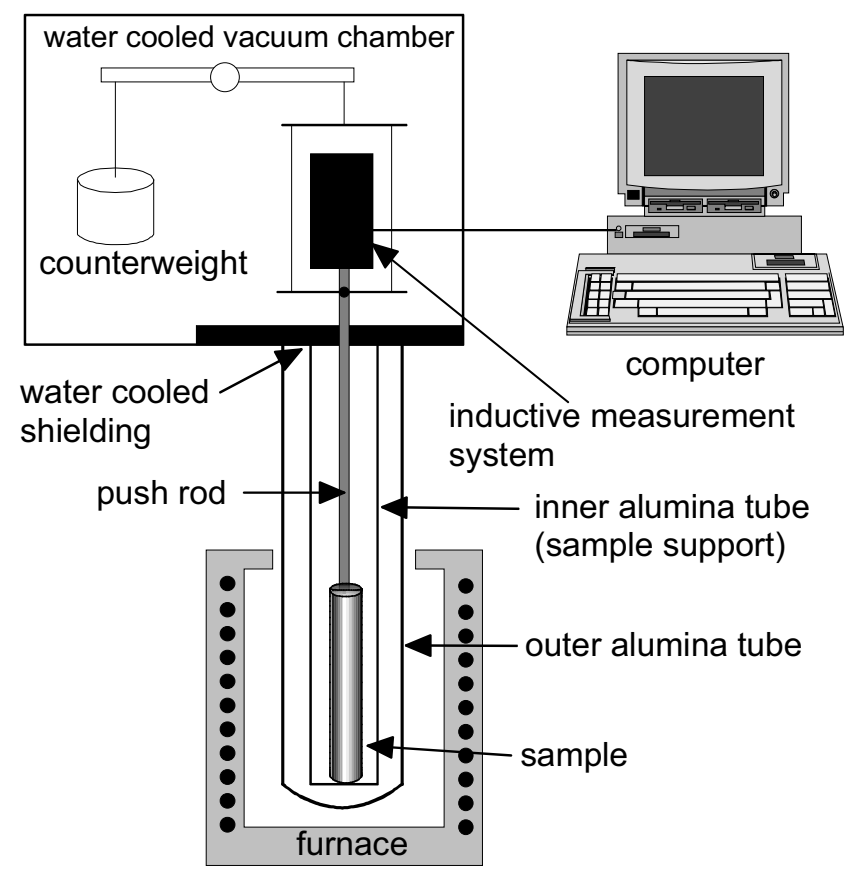

Figure 1: Schematic representation of the dilatometer. 


\section{DTA Measurements}

Comparative measurements, in particular on Waspaloy, were conducted with a Du Pont 910 thermal analyzer equipped with a TA Instruments 1600 DTA cell (A), and a TA Instruments 2910 module with 1600DTA cell (B). The main instrument parameters are compared in Table 3. Cell (A) was calibrated by utilizing commercially pure samples of $\mathrm{Zn}, \mathrm{Ag}$, and $\mathrm{Ni}$ and cell (B) by $\mathrm{Au}$ (99.999\%) and $\mathrm{Ag}(99.999 \%)$ standards.

Solid specimens were cut from small-diameter rods that had been previously machined from the standard heat-treated mill samples, and carefully cleaned. Prior to the first run, the DTA cells were thoroughly purged with the inert gas.

\section{Results and Discussion}

The results obtained with the Waspaloy material, since most detailed, are presented first. Figure 2 a shows a plot of the mean coefficient of thermal expansion for a reference temperature of $20^{\circ} \mathrm{C}$. During the first run, the material was initially in the standard heat treated condition per Table 2 . As a result of heating the sample above the $\gamma$ '-solvus, and subsequent cooling in the dilatometer, the $\gamma^{\prime}$ dispersion at the onset of any subsequent runs and, hence, the expansion curve will in general be different from that of the first run.

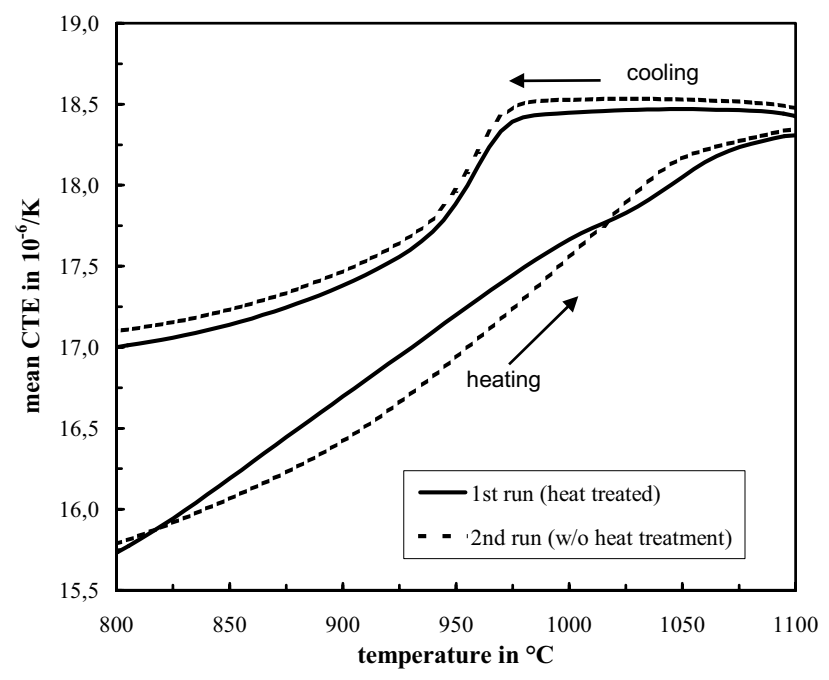

Figure 2a: Mean coefficient of thermal expansion (CTE) of the Waspaloy sample upon first and second heating. The heating and cooling rate were $10 \mathrm{~K} / \mathrm{min}$ each.

Inflection points in both the heating and cooling curves are apparent in Figure 2a. The offset of the heating and cooling curves discernable in Figure $2 \mathrm{a}$ at $1100^{\circ} \mathrm{C}$ is due to the calibration of the dilatometer with respect to a final temperature of $1200^{\circ} \mathrm{C}$. For that reason, the heating curves always represent the absolute CTE, while the CTE obtained from the cooling curves is shifted to higher values for final temperatures below $1200^{\circ} \mathrm{C}$. For the latter case, the temperature distribution of the whole system has changed in comparison with the calibration case. Presently, it cannot sufficiently be taken into consideration. The temperatures of the inflection points in Figure 2a, however, are virtually not affected by this offset.

Further discrimination between the curves is accomplished by plotting the instantaneous CTE (Figure 2b). The latter is in essence the first derivative of the mean CTE with respect to temperature:

instantaneous $\mathrm{CTE}=1 / \mathrm{l}_{\mathrm{o}} \mathrm{dl} / \mathrm{dT}$

whereby $l_{o}$ signifies the original specimen length, and $\mathrm{dl} / \mathrm{dT}$ the differential expansion. Notice that the Waspaloy sample, upon first heating, exhibited a double peak in the vicinity of the presumed $\gamma$ '-solvus, whereas upon second heating only a single peak was apparent. The cooling curves are almost identical, but exhibit a peak shift by about $70 \mathrm{~K}$ to lower temperatures. This observation can be generalized for a greater number of cycles : repeated cycling at the same heating and cooling rates led to virtually identical curves (Figure 3 ).

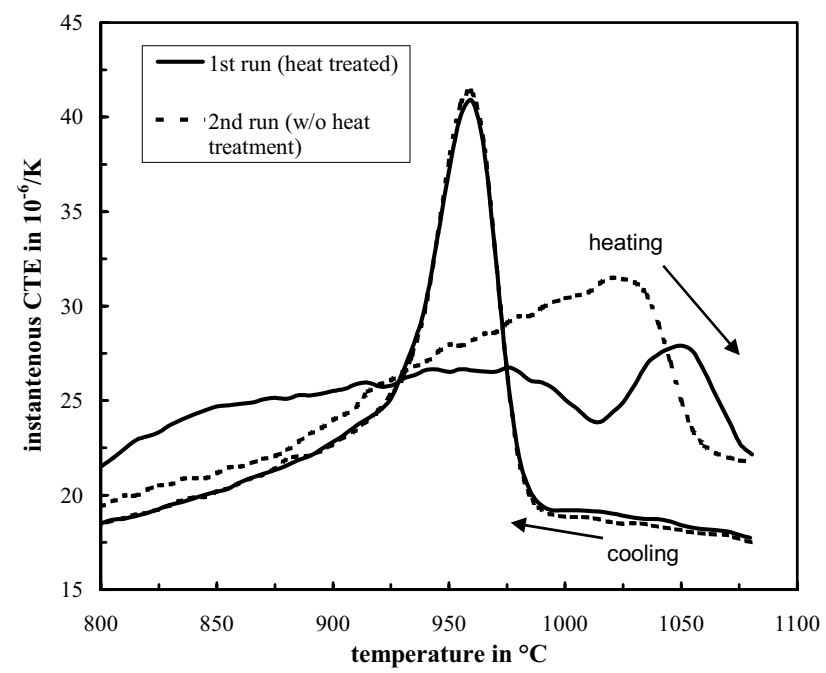

Figure 2b: Instantaneous coefficient of thermal expansion (CTE) of the Waspaloy sample upon first and second heating. The heating and cooling rate were $10 \mathrm{~K} / \mathrm{min}$ each.

Diminishing $\gamma^{\prime}$-double peak effects, as well as $\gamma^{\prime}$-peak shifts during successive DTA tests of the same sample have already been noted by Sponseller [4], who explained these effects by incremental homogenization of the dendritic structure of the cast samples studied. In this work, however, the double peak noticed upon heating in the course of the first CTE run was reproducible after re-applying the full heat treatment cycle (solutioning and aging) to the sample. In addition, the sample can be regarded as well homogenized because several CTE measurements were performed on that sample prior to the tests presented in Figure 3. For that reason, a $\gamma^{\prime}$-morphology effect is most likely, which is surmised to be due to the formation of different $\gamma^{\prime}$-size populations during the standard heat treatment. Metallographic inspection of a standard heat treated Waspaloy sample (see Table 2) revealed indeed coarse, sparsely distributed $\gamma^{\prime}$ precipitates in addition to the sub-microscopic aging $\gamma^{\prime}$. 
After eradicating the initial $\gamma^{\prime}$ dispersion by solutioning in the device, upon re-precipitation on cooling a rather uniform $\gamma$ '-size distribution can be expected to prevail. This, in turn, would lead to a single $\gamma$ '-solvus peak only during the subsequent heating cycle. This contention is also supported by the fact that the cooling curves featured only a single peak. Qualitatively similar results were obtained by DTA (Figure 4), again featuring a double peak upon first heating, and single peaks upon cycling in the DTA cell.

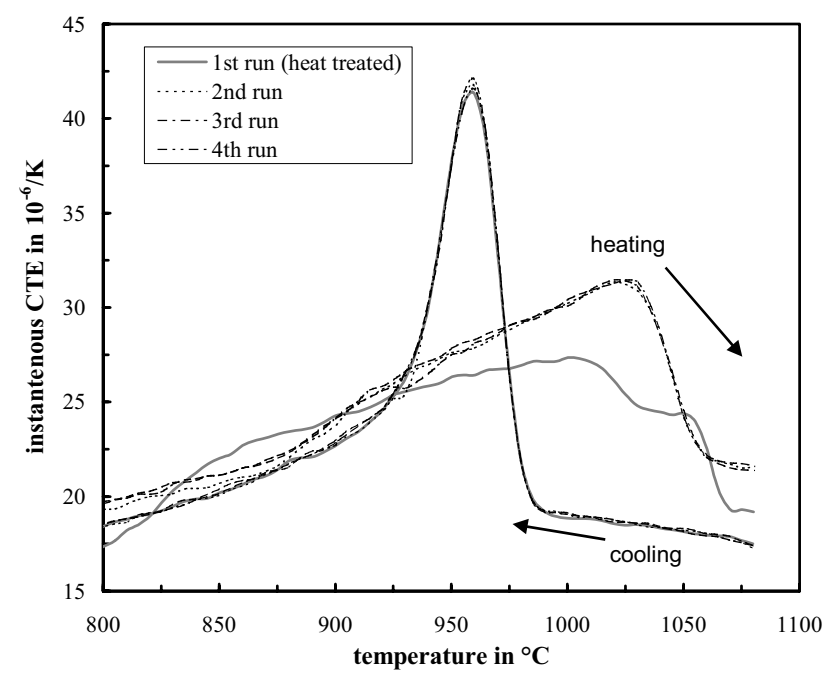

Figure 3: Instantaneous coefficient of thermal expansion (CTE) of the Waspaloy sample, measured upon repeated cycling at the same heating and cooling rate of 10 $\mathrm{K} / \mathrm{min}$.

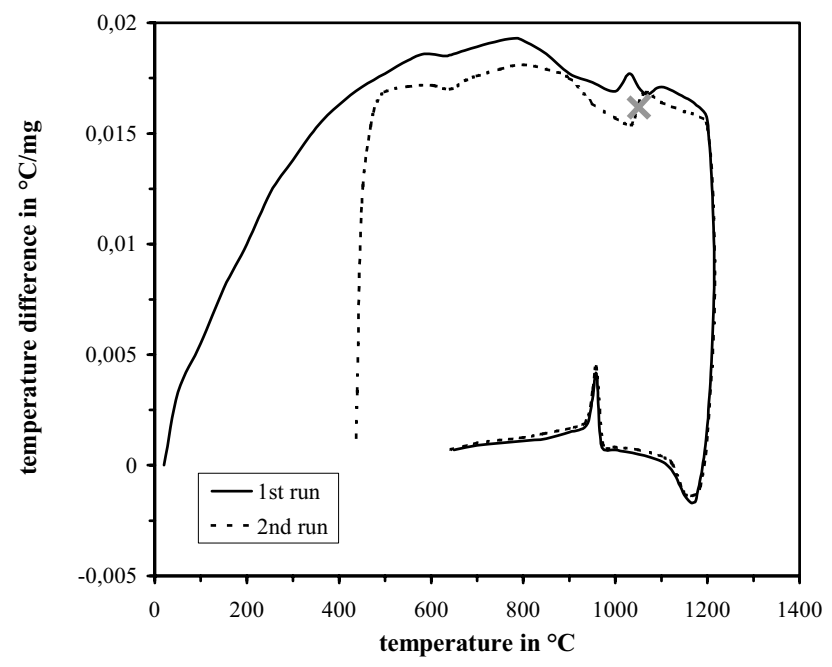

Figure 4: DTA trace of the Waspaloy sample upon repeated cycling. The heating rate was $40 \mathrm{~K} / \mathrm{min}$, and the cooling rate $20 \mathrm{~K} / \mathrm{min}$. Solid line: after standard heat treatment; dashed line: second run (after completion of the first cycle).
This combined experimental evidence suggests

- that the initial $\gamma$ ' dispersion can have a profound effect on the dissolution kinetics of this phase and, thus, its apparent solvus temperature,

- that the onset of $\gamma^{\prime}$ precipitation is greatly delayed relative to its dissolution, presumably due to nucleation barriers.

The apparent $\gamma$ '-solvus temperature based on second or higher number cycles will subsequently be discussed in detail since only such repeated cycling lead to a consistent signal. The dynamics involved in the measurement of the $\gamma^{\prime}$-solvus temperature becomes apparent when plotting the instantaneous CTE for different heating and cooling rates (Figure 5). The curves pertain to repeated cycles where the effect of the initial microstructure was lost. Consequently, only single peaks are discernible as discussed above.

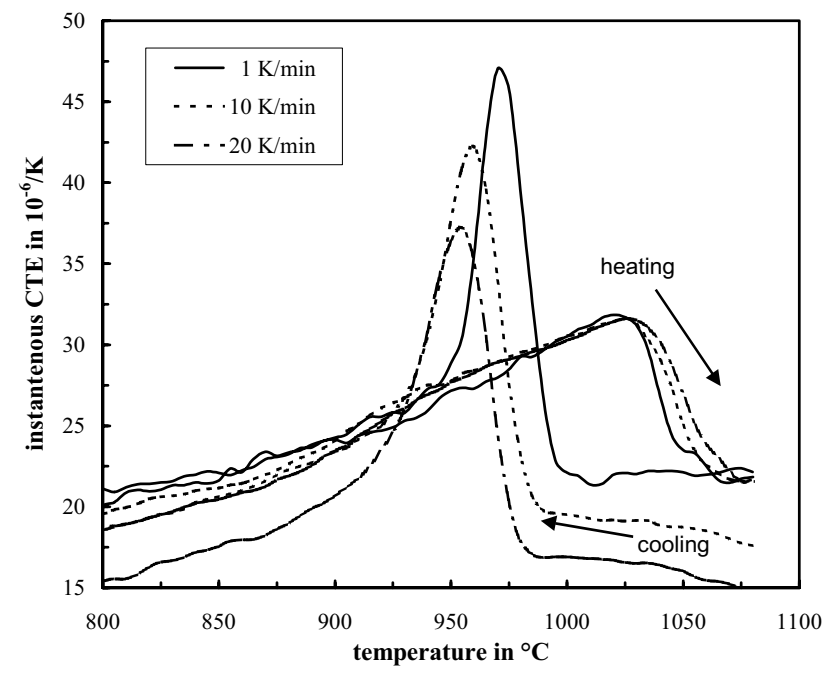

Figure 5: Instantaneous coefficient of thermal expansion (CTE) of the Waspaloy sample upon repeated cycling at different heating and cooling rates.

Note the peak shifts present upon heating and cooling. For kinetic reasons, higher heating rates would shift the dissolution peak to higher temperatures, and higher cooling rates would shift the precipitation peak to lower temperatures.

The kinetic factor was studied in greater detail by DTA. Figure 6 shows the effect of the cooling rate (in the DTA cell prior to heating) on the apparent $\gamma^{\prime}$-solvus temperature upon heating at 10 $\mathrm{K} / \mathrm{min}$. Here the inflection point marked by a $\mathrm{X}$ in Figure 4 was taken for the apparent $\gamma^{\prime}$-solvus. Arguably, there is some ambiguity involved in selecting this particular point on the DTA trace. However, this ambiguity is not uncommon to the evaluation of DTA traces. More importantly, a consistent procedure was employed.

It is known that slow cooling at rates of the order of $1 \mathrm{~K} / \mathrm{min}$ across the $\gamma^{\prime}$-solvus may result in very coarse dendritic $\gamma^{\prime}$ [5]. Dissolution of this coarse $\gamma^{\prime}$ upon heating will be very sluggish, shifting the apparent $\gamma$ '-solvus to higher temperatures as apparent from Figure 6. A relatively stable regime seems to have been reached for cooling rates greater than $10 \mathrm{~K} / \mathrm{min}$. According to the 
literature [5], such cooling rates should have resulted in a fine dispersion of spherical or cuboidal $\gamma$ ' precipitates which dissolve readily upon heating.

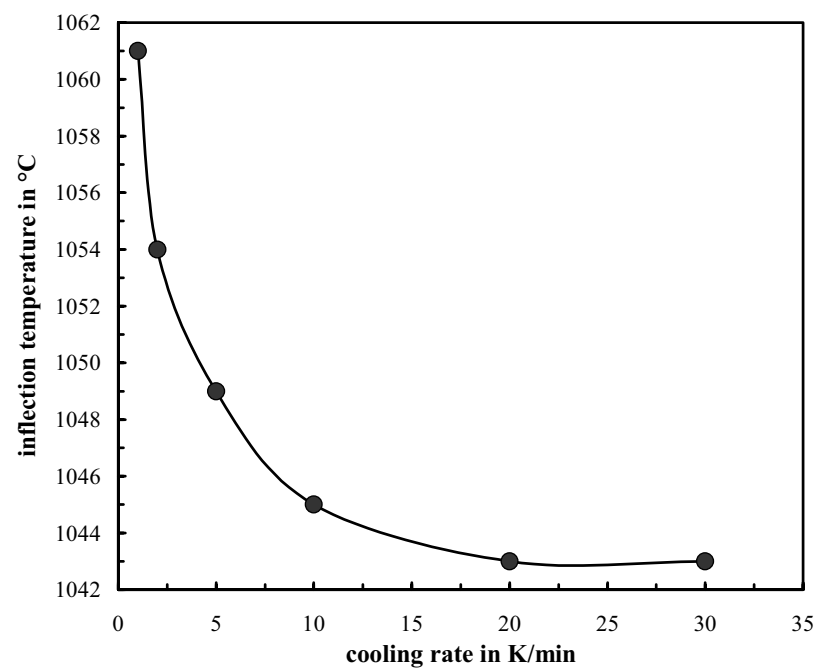

Figure 6: The apparent $\gamma^{\prime}$-solvus temperature of the Waspaloy sample measured upon heating at $10 \mathrm{~K} / \mathrm{min}$ is plotted as a function of the cooling rate in the DTA cell prior to heating.

Operating in this stable regime of cooling rates greater than 10 $\mathrm{K} / \mathrm{min}$, the apparent $\gamma^{\prime}$-solvus temperature upon heating still depends to some extent on the heating rate as shown in Figure 7. For the dilatometer measurements similar dependencies were found. Note that the maximum discrepancy of $10 \mathrm{~K}$ in the results of the two DTA cells and the dilatometer are within the margins of instrument calibration errors. Moreover, for the apparent "CTE" $\gamma$ '-solvus the local minimum in the second derivative of the mean CTE with respect to temperature (= location of highest curvature $=$ inflection point) was used which may or may not correspond to the aforementioned definition of the "DTA" solvus, thus resulting in a systematic offset.

Heating rates of $(5-10) \mathrm{K} / \mathrm{min}$ seemed to be a reasonable choice for the DTA measurements: lower heating rates resulted in unacceptable noise levels, whereas higher heating rates increasingly invoked kinetic effects. In contrast, heating rates as low as $1 \mathrm{~K} / \mathrm{min}$ could be employed in the dilatometer experiments thereby slightly further depressing the apparent $\gamma$ '-solvus temperature. This differential is, however, small in absolute terms. Good agreement between these values and the reported $\gamma$ '-solvus of $1047^{\circ} \mathrm{C}$ (metallographic technique) can be stated for this particular heat of Waspaloy [6]. It has to be kept in mind that the metallographically determined value generally represents an upper limit for the $\gamma^{\prime}$-solvus due to some banding caused by residual chemical inhomogeneity present even in a wrought material.

DTA measurements by Maurer et al. [7] and Sponseller [4] also revealed a moderate drop of the $\gamma^{\prime}$-solvus temperature when the heating rate decreases. Sponseller's [4] results on model alloys showed that the $\gamma^{\prime}$-solvus temperature measured at $10 \mathrm{~K} / \mathrm{min}$ lies about $15 \mathrm{~K}$ above the solvus temperature determined by metallography. Further investigations [4] with heating rates of 2 $\mathrm{K} / \mathrm{min}$, however, agreed closely with metallographic studies. For that reason, Sponseller [4] recommended the determination of $\gamma$ 'solvus temperatures at very low heating rates, because those are more representative of a, e.g., 2-hr heat treatment or soak prior to hot working.

The results of the apparent $\gamma^{\prime}$-solvus temperature measurements for the other alloy studied, NIMONIC alloy 80A, under the aforementioned "optimum" conditions, i.e., a cooling rate of 20 $\mathrm{K} / \mathrm{min}$, are shown in Figure 8.

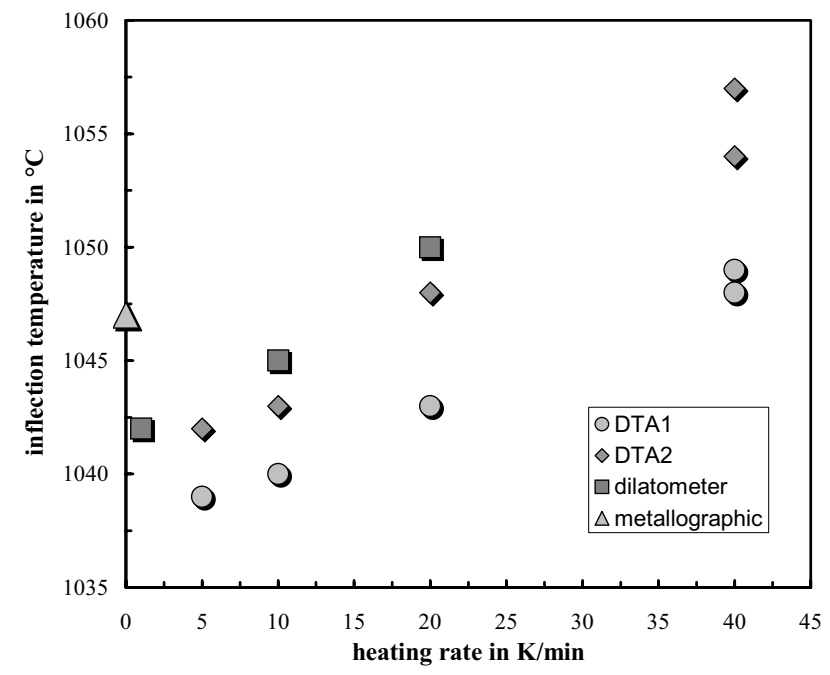

Figure 7: The apparent $\gamma$ 'solvus temperature of the Waspaloy samples measured after repeated cycling is plotted as a function of the heating rate. The dilatometer measurements were performed at the same heating and cooling rates as the DTA experiments.

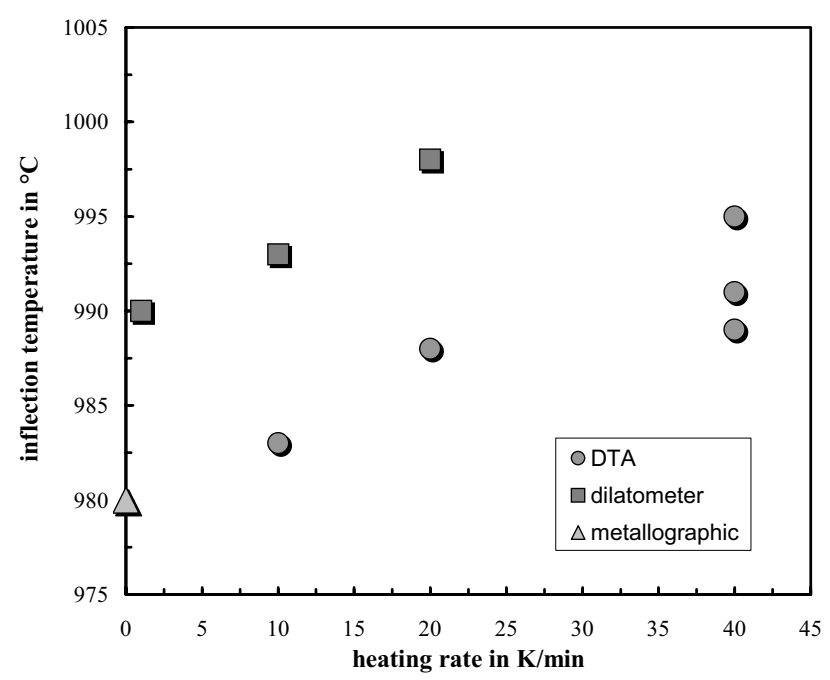

Figure 8: The apparent $\gamma^{\prime}$-solvus temperature of NIMONIC alloy $80 \mathrm{~A}$ after repeated cycling is plotted as a function of the heating rate. The cooling rate was consistently $20 \mathrm{~K} / \mathrm{min}$ The dilatometer measurements were performed at the same heating and cooling rates. 
The systematically higher "CTE" $\gamma$ '-solvus temperature may again, as discussed earlier, be the result of the somewhat different definitions of the respective inflection points. More importantly, the maximum difference between the DTA and the CTE as well as the metallographic results amounts to less than $10 \mathrm{~K}$, which is well within the temperature control margin of industrial heating furnaces. This good agreement over a sizable range in absolute $\gamma$ 'solvus temperatures from roughly $980^{\circ} \mathrm{C}$ to $1050^{\circ} \mathrm{C}$ as covered by the examined alloys suggests that measurement of the inflection temperature in thermal expansion curves indeed merits consideration for an industrial practice. In addition, this technique seems to feature the resolution necessary to be useful as a quality assurance tool in light of a reproducibility of better than $5^{\circ} \mathrm{C}$ in the results from second and higher order cycles.

\section{Summary and Conclusions}

The $\gamma^{\prime}$-solvus temperatures of two commercial wrought Ni-base superalloys, i.e., Waspaloy and NIMONIC alloy 80A, were determined independently by differential thermal analysis (DTA) and measurement of the mean coefficient of thermal expansion (CTE), specifically a well-pronounced inflection point thereof. The signals obtained upon first time heating depended greatly on the prior heat treat condition. Repeated cycling through the $\gamma^{\prime}$ solvus temperature range, however, resulted in consistent and reproducible signals. Under these conditions, agreement within $10 \mathrm{~K}$ was found between the "DTA" solvus, the "CTE" solvus and the "metallographic" solvus, provided the same heating and cooling rates were employed.

In conclusion, it appears that measurement of the $\gamma^{\prime}$ solvus temperature in wrought $\mathrm{Ni}$-base superalloys by the thermal expansion method merits consideration for a viable alternative to the more common DTA or metallographic methods. It is suspected that this is also true for cast $\gamma^{\prime}$ hardenable Ni-base superalloys. Attention has to be paid to instrument operating parameters and the associated in-situ microstructures in order to minimize any kinetic effects and, thus, obtain values most closely representing thermodynamic equilibrium. It is this very aspect where the "CTE" method excels over the "DTA" method since it allows for exceedingly slow heating rates. In addition, the larger sample sizes employed in the former method should, in principle, yield more representative results.

Lastly, it has to be critically questioned to what extent any of these in-situ microstructures are representative of industrial conditions.

\section{Acknowledgments}

The authors are grateful to Mr. W. Langner for conducting the thermal expansion measurements, and Mrs. I. Lutz for her help with the heat treatment of the samples. DTA data provided by and helpful discussion with Dr. X. Pierron are acknowledged.

\section{References}

[1] H. Morrow, D. L. Sponseller, and M. Semchyshen, Met. Trans. 6A (1975) 477.
[2] W. Hermann and H.-G. Sockel, Elastictiy of hightemperature alloys, in Microstructure and Mechanical Properties of Metallic High-Temperature Materials, Edited by H. Mughrabi, G. Gottstein, H. Mecking, H. Riedel and J. Tobolski, Deutsche Forschungsgemeinschaft, WILEY-VCH, Weinheim (1999) 337-355.

[3] P.M.L. Klose, Doctoral Thesis, University Erlangen Nürnberg, 1987.

[4] D.L. Sponseller, Differential Thermal Analysis of NickelBase Superalloys, in Superalloys 1996, Edited by R.D. Kissinger, D.J. Deye, D.L. Anton, A.D. Cetel, M.V. Nathal, T.M. Pollock, and D.A. Woodford, The Minerals, Metals \& Materials Society (1996) 259-270.

[5] M. F. Henry, Y. S. Yoo, D. Y. Yoon, and J. Choi, Met. Trans. 24A (1993) 1733.

[6] Special Metals Corporation, Huntington, West Virginia, USA, internal data.

[7] G.E. Maurer, J. Domingue, and W.J. Boesch, Superalloy Design with Differential Thermal Analysis, in Proceedings of the 27th Annual Meeting of the Investment Casting Institute, Rosemont, 